\title{
Does a lower diagnostic threshold of sensitive plasma troponin I assay improve clinical outcomes of patients with chest pain?
}

\author{
Francesca Perego $\cdot$ Franca Dipaola $\cdot$ \\ Gruppo di Autoformazione Metodologica (GrAM)
}

Received: 6 August 2011/Accepted: 15 October 2011/Published online: 1 November 2011

(c) SIMI 2011

\section{Background}

Recent reports have indicated that the latest generation of sensitive troponin assays can increase diagnostic performance, and improve the early diagnosis of myocardial infarction (MI) [1, 2]. However, it is not clear whether lowering the diagnostic threshold for MI with a sensitive troponin test can improve clinical outcomes in patients with chest pain.

\section{Summary}

In the study by Mills et al. [3] consecutive patients admitted to the Royal Infirmary of Edinburgh for a chest pain of suspected cardiac origin were enrolled. For each patient included, the value of troponin I concentrations on admission, $12 \mathrm{~h}$ after symptom onset, or both had to be available. Patients with non-cardiac (respiratory, gastrointestinal, or musculo-skeletal) chest pain or those for whom follow-up was not possible were excluded. The study was divided into two phases (validation and implementation), performed 1 year apart, each one enrolled different groups

\section{F. Perego ( $₫)$}

Medicina III, "Luigi Sacco" Hospital,

University of Milan, via G.B. Grassi 74, 20154 Milan, Italy

e-mail: francescap.p@libero.it

\section{F. Dipaola}

Medicina Interna, "Istituti Clinici di Perfezionamento",

Sesto S. Giovanni, Milan, Italy

Gruppo di Autoformazione Metodologica (GrAM)

University of Milan, Milan, Italy of patients. Although throughout the study the same test was performed (Abbott Architect assays), in the validation phase the original diagnostic threshold of troponin concentration of $\geq 0.20 \mathrm{ng} / \mathrm{mL}$ was used, whereas in the implementation phase the revised threshold of $\geq 0.05 \mathrm{ng} /$ $\mathrm{mL}$ was considered. Patients of both phases were then stratified into three groups based on the peak values of plasma troponin concentrations $(<0.05 \mathrm{ng} / \mathrm{mL}$; between 0.05 and $0.19 \mathrm{ng} / \mathrm{mL} ; \geq 0.20 \mathrm{ng} / \mathrm{mL}$ ). The main outcomes were MI recurrences and deaths at 1 year. 2,092 patients with suspected acute coronary syndrome (ACS) were included in the study, 1,038 in validation and 1,054 in implementation phase.

Regarding the clinical management, in the validation phase, patients with troponin concentrations between 0.05 and $0.19 \mathrm{ng} / \mathrm{mL}$ were less likely to be referred to a cardiologist (44 vs. 93\%), to receive dual antiplatelet therapy (27 vs. $80 \%$ ) or be subjected to revascularization (17 vs. $59 \%)(p<0.001$ for all comparisons) than patients with troponin concentration of $\geq 0.20 \mathrm{ng} / \mathrm{mL}$.

In the implementation phase, the management of patients with troponin values between 0.05 and $0.19 \mathrm{ng} / \mathrm{mL}$ improved when compared to validation phase (cardiology referral 74 vs. $44 \%$; dual antiplatelet therapy 58 vs. $27 \%$; coronary angiography procedure 46 vs. $20 \% ; p<0.001$ for all comparisons).

Patients included during the validation phase had a median follow-up of 453 days. In this group, those with troponin concentrations between 0.05 and $0.19 \mathrm{ng} / \mathrm{mL}$ had higher probability of death at 12 months $(25 \%)$ or new hospitalization for MI (31\%) compared with patients with troponin $<0.05 \mathrm{ng} / \mathrm{mL}$ ( 4 and $5 \%$, respectively) and troponin $\geq 0.20$ (13 and $18 \%$, respectively). From validation to implementation phase, $29 \%$ increase in the frequency of diagnosis of MI was observed. 
Patients admitted after the introduction of sensitive troponin assay in clinical practice were followed for a median of 451 days. The proportion of patients experiencing death or readmission for MI at 12 months compared to validation period was unchanged for patients with troponin $<0.05 \mathrm{ng} / \mathrm{mL}$ ( 7 vs. $5 \%$, OR $0.69,95 \%$ CI $0.44-1.10$, $p=0.11$ ) and troponin $\geq 0.20$ (24 vs. $24 \%$, OR $0.98,95 \%$ CI $0.67-1.44, p=0.92$ ). On the other hand, reducing the diagnostic threshold to $0.05 \mathrm{ng} / \mathrm{mL}$ significantly improved the clinical outcomes in patients with troponins between 0.05 and $0.19 \mathrm{ng} / \mathrm{mL}$ (39 vs. 21\%, OR $0.42,95 \%$ CI $0.24-0.84, p=0.01)$.

Therefore, the authors concluded that lowering the diagnostic troponin threshold for MI increases the diagnosis of MI, and brings to the patients with suspected ACS an immediate and substantial improvement in clinical management and outcomes.

\section{Strengths of the study}

- The study is well designed and has a valid rationale.

- The cardiovascular outcome has a high clinical relevance.

- Laboratory methods and diagnostic thresholds are clearly described.

\section{Weaknesses of the study}

- Baseline clinical characteristics (percentages of men, previous revascularization, previous stroke, peripheral vascular disease, TIMI risk score mean) of validation and implementation cohorts are not similar (validation vs. implementation cohort $p=0.03, p=0.03, p=$ $0.001, p=0.02$ and $p=0.03$, respectively); results could be affected by this difference.

- The external validity of the study could be questioned because the inclusion criteria might be too restrictive. Indeed, in clinical practice, the use of troponin assay is particularly useful in the differential diagnosis of patients with atypical chest pain, who were excluded from the study.

- Information about the patients' renal functions was not reported, also essential to interpret troponin values.

\section{Question marks}

- It is not clear the setting where the patients were evaluated. In particular, it is not mentioned if troponin was collected during a visit in the emergency department or in the other acute settings.

- When the lower diagnostic threshold of plasma troponin concentrations was applied, a higher number of coronary angiography and more cardiology referrals were performed. It would be very interesting to know if the diagnostic pathway is cost-effective in the patient group with troponin values between 0.05 and $0.19 \mathrm{mg} / \mathrm{dL}$.

\section{Sponsorship}

- No funding organization or sponsor played a role in the design and conduct of the study.

\section{Clinical bottomline}

In an hospital selected patient cohort with typical presentation of chest pain, implementation of a sensitive troponin assay identified patients at high risk of recurrent MI and death, in particular, when a lower diagnostic threshold of plasma troponin was applied.

Caution should be used in generalizing the results to patients with atypical chest pain.

Conflict of interest None.

\section{References}

1. Reichlin T, Hochholzer W, Bassetti S et al (2009) Early diagnosis of myocardial infarction with sensitive cardiac troponin assays. N Engl J Med 361:858-867

2. Keller T, Zeller T, Peetz D et al (2009) Sensitive troponin I assay in early diagnosis of acute myocardial infarction. $\mathrm{N}$ Engl $\mathrm{J}$ Med 361:868-877

3. Mills NL, Churchhouse A, Ken Lee K et al (2011) Implementation of a sensitive troponin I assay and risk of recurrent myocardial infarction and death in patients with suspected acute coronary syndrome. JAMA 305:1210-1216 